\title{
Maximization of Wind Energy Utilization through Corrective Scheduling and FACTS Deployment
}

DOI:

10.1109/TPWRS.2017.2662802

\section{Document Version}

Accepted author manuscript

Link to publication record in Manchester Research Explorer

\section{Citation for published version (APA):}

Kapetanaki, A., Levi, V., \& Buhari, M. (2017). Maximization of Wind Energy Utilization through Corrective Scheduling and FACTS Deployment. IEEE Transactions on Power Systems.

https://doi.org/10.1109/TPWRS.2017.2662802

\section{Published in:}

IEEE Transactions on Power Systems

\section{Citing this paper}

Please note that where the full-text provided on Manchester Research Explorer is the Author Accepted Manuscript or Proof version this may differ from the final Published version. If citing, it is advised that you check and use the publisher's definitive version.

\section{General rights}

Copyright and moral rights for the publications made accessible in the Research Explorer are retained by the authors and/or other copyright owners and it is a condition of accessing publications that users recognise and abide by the legal requirements associated with these rights.

\section{Takedown policy}

If you believe that this document breaches copyright please refer to the University of Manchester's Takedown Procedures [http://man.ac.uk/04Y6Bo] or contact uml.scholarlycommunications@manchester.ac.uk providing relevant details, so we can investigate your claim.

\section{OPEN ACCESS}




\title{
Maximization of Wind Energy Utilization through Corrective Scheduling and FACTS Deployment
}

\author{
A. Kapetanaki, Student Member, IEEE, V. Levi, Senior Member, IEEE, M. Buhari, Student Member
}

\begin{abstract}
The paper proposes a probabilistic methodology for minimizing wind spillage and maximizing capacity of the deployed wind generation, whilst improving system reliability. Capacities of the connected wind units are initially determined by using a method developed by the industry. A probabilistic approach is applied for the day-ahead planning to find maximum deployable wind sources so that the prescribed wind spillage is not exceeded. This is done using the optimum power flow, where wind spillages are prioritised with the probabilistic 'cost coefficients'. Further improvement of wind energy utilization is achieved by installing FACTS devices and making use of realtime thermal ratings (RTTR). Two ranking lists are developed to prioritize location of SVCs and TCSCs, and they are then combined into a unified method for best FACTS placement. The entire methodology is realized in two sequential Monte Carlo procedures, and the probabilistic results are compared with the state enumeration ones. Results show improved wind utilization, network reliability and economic aspects.
\end{abstract}

Index Terms-Wind generation utilization, contracted obligations, spillage prioritization, corrective scheduling, FACT devices, RTTR, reliability, sequential Monte-Carlo simulation

\section{INTRODUCTION}

Connection of wind energy sources has continuously grown over the last decade, leading to saturation and deferral of new wind connections in some countries [1], [2]. The size of wind capacity that can be accommodated is driven by thermal and voltage constraints, fault ride-through and stability capabilities, required spinning reserve, etc. [3]-[5]. Once wind units are connected, system operator needs to consider both network security and contractual obligations with generators; the latter is usually expressed in terms of maximum allowable wind curtailment or 'spillage' [6] [7]. An example of wind management in the French system is presented in the policy document [8]. The operator needs to apply various controls to keep the wind spillage under the prescribed level.

Different aspects of wind energy integration have been investigated in [3] -[17]. Hydro-pumped storage is used in [3] to increase deployed wind power during disturbances, whilst studies [7][9][10] use energy storage to consume surplus wind production. Research in [4] determines how increased wind integration affects the system reliability, stochastic unit

This work was supported by EPSRC within the HubNet project under Grant $\mathrm{EP} / \mathrm{I013636/1}$

The authors are with the School of EEE, Electrical Energy Division, University of Manchester, UK(email:alexandra.kapetanaki@manchester.ac.uk victor.levi@manchester.ac.uk; muhammad.buhari@manchester.ac.uk ). commitment with wind generation (but without lost load) is introduced in [5], whilst two categories of wind curtailment, voluntary and involuntary, are defined in [6] to model real-life contracts. Maximization of connected wind sources to meet deterministic security criteria is done in [11], [12] without optimizing spillage levels; it was also not recognised that maximum wind capacities should be found with the aid of a probabilistic approach in order to satisfy contracted wind spillages on an annual basis (e.g. percentage of annual MWh production). Reliability studies, which include probabilistic wind modelling, such as [13]-[15], do not even include wind spillages; the approaches did not consider that load and wind curtailments should be jointly treated. Integration of even higher levels of wind generation can be achieved through network reinforcements [13][16][17], yet only the approach in [17] considers wind curtailment cost term. Several approaches for optimal placement and sizing of FACTS were developed, with the objective to minimize real power losses [18], to improve system loadability [19] and to minimize the total fuel cost [20]. Interactions between FACTS and renewable sources are analysed in [21][22][23]; however, the optimal locations and performance of FACTS are evaluated for intact networks only. Finally, to the best of the authors' knowledge, no research was done to investigate the combined impact of SVCs, TCSCs and RTTRs on the maximum utilization of wind energy sources.

The paper proposes a probabilistic methodology for the best utilization of wind energy sources in the day-ahead operations planning. The objective is to determine maximum deployable wind generations by hourly intervals so that the expected minimized wind curtailment satisfies contractual obligations. Wind units are owed by third parties, whose connection contracts specify the maximum level of voluntary curtailment [6] [8], whilst involuntary ones go above contracted amounts in case of system emergencies. The methodology is realized with the aid of two sequential Monte Carlo simulation (SMCS) procedures, which make use of the optimum power flow (OPF) for corrective rescheduling. The objective is to minimize hourly operation costs, which contain both load and wind curtailments. Our studies have shown that much improved results are obtained when wind curtailments are prioritized with the probabilistic cost coefficients. If the optimal wind spillages are below contracted values, additional wind sources can be deployed until contractual obligations are met. Results from the SMCS runs are minimised wind spillages, maximised hourly deployable wind capacities and reliability and operation cost indices. Additional investigations are done to find impact of SVCs, TCSCs and RTTR on the 
maximum utilisation of wind sources. A ranking list of best nodes for the SVC connection is based on load and wind curtailments caused by voltage limits, whilst branches best candidates to install TCSCs are ranked using their contribution towards reduction of load \& wind shedding due to thermal constraints. These two lists are then combined within a procedure to find best locations for placement of SVCs and TCSCs. The SMCS results are compared against the state enumeration results.

\section{OVERVIEW OF THE METHODOLOGY}

Objectives of the probabilistic approach for day-ahead planning of systems with large penetration of wind are threefold: a) Maximize deployed wind generation to meet contractual obligations; b) Increase overall system reliability; and c) Reduce system operation cost including costs of curtailed load and wind. The objectives are achieved by following corrective actions: a) Reschedule dispatchable generation; b) Curtail load and wind generation; c) Install SVCs and TCSCs; and d) Deploy RTTR on overhead lines.

The overall methodology consists of two simulation stages, as shown in Fig.1. The first, SMCS $^{1}$, is preparatory and it delivers outputs, which are required by the second stage $\mathrm{SMCS}^{2}$. The main building blocks of the first stage are:

- Connection of wind generation using an industry method.

- Probabilistic analysis of the 24-hour period within base SMCS $^{1}$ with unity costs associated with wind spillages.

- Determining base expected energy not supplied (BEENS), base expected spillage $(B E S P)$, wind spillage 'cost coefficients', voltage histograms for ranking of SVCs, as well as BEENS and BESP increments for TCSC ranking.

- $\quad$ Procedure for placement of SVCs and TCSCs.

Maximum utilization of wind sources with different controls is investigated in the second simulation stage. Two different methodological approaches are studied: a) The $\mathrm{SMCS}^{2}$ procedure; and $\left.\mathrm{b}\right)$ the state enumeration based on $(\mathrm{N}-$ 1) outages. The essential building blocks are the same for both

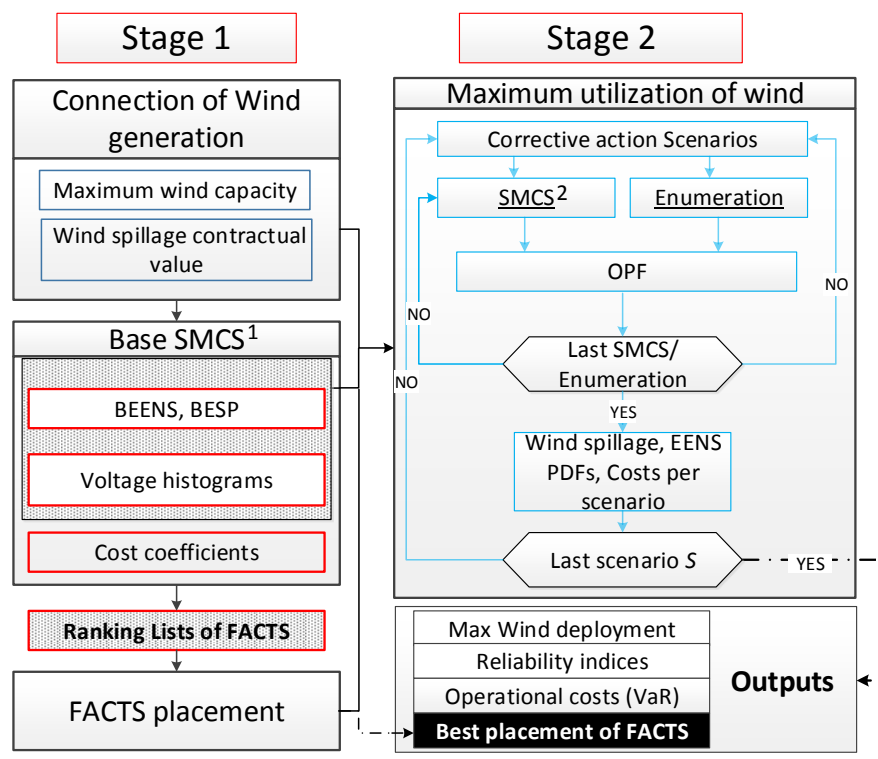

Fig. 1: Methodology for maximum utilization of wind generation methodologies - see Fig. 1. The following corrective action scenaria are executed in this stage:

- Scheduling scenario': generation rescheduling and curtailment of wind \& load is considered to maximize wind utilization; RTTR may also be included.

- 'Scheduling and FACTS scenario': generation and load rescheduling with placement of SVCs and/or TCSCs is done; RTTR may also be included.

- 'Increased deployed wind scenario': this can be either 'scheduling' or 'scheduling \& FACTS scenario' whereby wind capacities are increased until contract limits are met.

\section{FIRST SIMULATION STAGE}

\section{A. Connection of Wind Generation}

To speed-up connection process, utilities often provide developers with maximum permissible generation capacities that can be connected at system nodes. The calculation can be done using either formula-based approach [8], or more complex iterative load-flow method [24]. The non-firm connection denotes calculations based on the intact network, whilst firm connection implies single circuit outages [11][12].

The formula based approach, also applied by the French transmission system operator RTE [8], is developed for the most onerous operating regime, which is, for generation integration, the summer minimum when the load and line capacities are smallest. The approach is based on the first Kirchhof's Law, so that maximum connection capacity $P_{W G i}^{\max }$ of wind generation at node $i$ is:

$P_{W G i}^{\max }=\left(P_{D i}^{\min }+p r_{i} \cdot \sum_{l} S_{l}^{S T R}-P_{G i}^{u p}\right) / \beta$

where $P_{D i}^{\min }$ is minimum load at node $i, p r_{i}$ is proportion of capacity of circuits connected to node $i$ deemed available for wind generation export (dependent on location, takes into account power factor), $S_{l}^{S T R}$ is line $l$ seasonal thermal rating (STR) in MVA, $P_{G i}^{u p}$ is existing generation at node $i$, and $\beta \varepsilon$ $[0,1]$ is the ratio of the expected wind speed during summer minimum with respect to the winter maximum speed (typically 0.8 in RTE [25]). Empirical factor $\beta<1$ is introduced because wind speeds are higher in wintertime, loads and circuit capacities are also higher and more wind capacity can be connected and exported from node $i$. Summation in (1) goes over all lines $l$ connected to node $i$ in case of non-firm connection, or over all lines $l$ but the one with highest capacity in case of firm connection. The total wind generation that can be connected at all nodes in the network is limited to [13]:

$\sum_{i} P_{W G i}^{\max } \leq \delta \cdot P_{D}^{\text {peak }} / w f$

where $\delta$ is percentage of peak demand that can be supplied by wind generation, $P_{D}^{\text {peak }}$ is system peak demand and $w f \varepsilon[0,1]$ is wind factor indicating percentage of total wind capacity utilized to supply peak demand.

The main idea of the load-flow based approach [24] is to connect a 'new' generator at node $i$, to gradually increase its production and run $\mathrm{AC}$ power-flow until one of thermal or voltage constraints is not reached. In case of wind generation, 
the maximum generation capacity obtained with $\mathrm{AC}$ power flow analysis is further divided by factor $\beta$ as in (1). In this way, both non-firm and firm connection capacities can be determined.

\section{B. Sequential Monte Carlo Simulation}

The basic features of the SMCS procedure are given below. Section a) presents details common to both $\mathrm{SMCS}^{1} \& \mathrm{SMCS}^{2}$.

\section{a) Random Sampling, Wind Generation and RTTR}

The relevant chronological phenomena are wind generation, load profiles, load curtailments with load recoveries and RTTR. All network components and generation units are modeled using the two-state Markov model [26]. Load varies in a window around the forecast hourly loads, which is found using the neural network approach [27]. An $\operatorname{ARMA}(4,3)$ stochastic process is fitted to the normalized historic wind speeds, which are then used to calculate wind turbine active power outputs in each hour $t$ [23].

The STR and RTTR are used in SMCS procedures as OHL thermal ratings. Different maximum conductor temperatures by seasons are allowed as STR [28]. RTTR analysis considers steady-state thermal equilibrium in each hourly period within the IEEE thermal balance model [29]. The hourly RTTR is a function of conductor temperature, which is set to one of design values (ie $50^{\circ} \mathrm{C}, 65^{\circ} \mathrm{C}, 75^{\circ} \mathrm{C}$ ) to get the $\mathrm{OHL}$ ampacity.

One SMCS period is equal to 24 hours and simulations are repeated until convergence is obtained. All simulations are done for the winter peak and summer minimum days. All results from the first stage $\mathrm{SMCS}^{1}$ are denoted with a prefix ' $B$ ' indicating 'base' values. They are used for prioritization of spillages, placement of FACTS, etc. in the $\mathrm{SMCS}^{2}$.

\section{Prioritization of Wind Curtailments}

All OPF calculations in the $\mathrm{SMCS}^{1}$ are done with equal costs of wind spillages. The results indicated that it would be advantageous to prioritize wind spillages by associating different 'cost coefficients'. The 'cost coefficients' should be proportional to 'appropriate' reliability index, which reflects stochastic requirements for wind spillage at different points. Wind spillages are classified as voluntary and involuntary [6]; the former is limited by the contracted average spillage (usually around 5\% [8]) and priced at contractual price $\sigma$ (we have used $\sigma=55.5 £ / M W h$ [9]). Involuntary spillages are limited by the available wind production and are priced at locational marginal prices that give additional cost for one extra unit of demand that is equivalent to unit generation curtailment. The cost coefficients are defined as:

$\xi_{i}=\left\{\begin{array}{cc}\overline{\overline{B E S P}}_{i}^{r e l} \cdot \sigma \quad \text { voluntary spillage } \\ \overline{\overline{B E S P}}_{i}^{\text {rel }} \cdot \mu_{i}^{p} \quad \text { involuntary spillage }\end{array}\right.$

$\operatorname{BESP}_{i}^{r e l}=\sum_{y=1}^{Y} \sum_{t=1}^{T}\left(\frac{S P_{i}^{y, t}}{P_{W G i}^{u p}}\right) / Y$

where $\xi_{i}$ is spillage cost at node $i, B E S P_{i}^{\text {rel }}$ is expected relative spillage at node $i$ in the first $\mathrm{SMCS}^{1}, \sigma$ is contracted price, $\mu_{i}^{p}$ is $p$-th percentile of base marginal price at node $i, Y$ is total number of simulated days, $T=24 h, S P_{i}^{y, t}$ is active power spillage at node $i$ day $y$ hour $t$ from OPF results, and $P_{W G i}^{u p}$ is (sampled) wind active power generation. $\overline{\overline{B E S P}}_{i}^{\text {rel }}$ in eq. (3) is normalized expected spillage at node $i$; normalization is done with $\Sigma_{i} B E S P_{i}^{r e l}$ so that sum of all normalized spillages is equal unity. Cost coefficients (3) are defined for the entire 24-hour period; an option to find hourly spillage cost coefficients by 24 hourly periods was also investigated.

\section{Placement of SVCs and TCSCs}

Placement of FACTS is done in two stages: two ranking lists for SVCs and TCSCs are established first, and then an algorithm is developed to combine these two lists.

\section{a) Ranking of SVCs}

Ranking of SVCs is based on the following assumptions: a) SVCs are installed when violation of voltage constraints exists or when voltages are close to the limits; and b) SVCs are placed at nodes where the voltage problems are highest.

Essential indicators used to build the ranking list are expected curtailed loads BEENS and curtailed winds BESP. In the base $\mathrm{SMCS}^{1}$ they are treated as voltage related at those nodes where the relevant voltage constraint is binding. The corresponding daily nodal curtailments are $B E E N S_{i}^{\text {volt }}$ and $B E S P_{i}^{\text {volt }}$. To consider feasible voltages close to the limits that can be easily exceeded under varied conditions, voltage histograms $\gamma_{i}=\left\{V_{i}{ }^{l}, \ldots, V_{i}^{t}, \ldots, V_{i}^{24 Y}\right\}$ at nodes $i$ are recorded and the following quantities computed:

$\Delta \gamma_{i}^{V^{\min }}(\psi)=\frac{1}{Y} \sum_{V^{\min }}^{V^{\min }+\psi}\left(\gamma_{i}-V^{\min }\right)$

$\Delta \gamma_{i}^{V^{\max }}(\psi)=\frac{1}{Y} \sum_{V^{\max }}^{V_{-\psi}^{\max }}\left(V^{\max }-\gamma_{i}\right)$

which represent total daily nodal voltage deviations from the lower (5) and upper limit (6) in a pre-specified per unit region $\psi$. These deviations are then included into the developed criterion for ranking of nodes for SVC connection:

$\rho_{i}=\left(\tau_{1} B E E N S_{i}^{\text {volt }}+\tau_{2} B E S P_{i}^{\text {volt }}\right)\left[1+\Delta \gamma_{i}^{V^{\text {min }}}(\psi)+\Delta \gamma_{i}^{V^{\text {max }}}(\psi)\right]$

where $\tau_{1}$ and $\tau_{2}$ are weights showing relative importance of load curtailment compared to wind spillage. If reliability is preferred to wind spillages, ratio $\tau_{1} / \tau_{2}$ can be set to the ratio of the value of lost load to the average spillage cost; where wind spillages play more important role, this ratio can be set to unity. Criterion (7) shows that ranking of SVCs considers both lost load and spillage whilst looking into uncertain future expressed through interior voltage deviations (5) \& (6).

\section{b) Ranking of TCSCs}

Essential assumptions used for ranking of TCSCs are: a) TCSCs are installed when energy curtailments occur due to violation of capacity constraints; b) Numerical sensitivity analysis of OPF solutions is applied to define branches best candidates for TCSC installation; and c) The initial set of branches candidates for TCSC placement is based on available thermal capacity margins of the branches.

The objective is to find a set of branches whose reduction in reactance gives the maximum reduction in load and wind curtailments. The numerical sensitivity analysis of the OPF solution has been applied due to the non-linear nature of the problem. The main algorithmic steps are: 
1) Consider a $\mathrm{SMCS}^{1} \mathrm{OPF}$ solution and find binding capacity constraints. If there are no such constraints, repeat step No. 1 for the next hourly period.

2) Find the set of branches ij $\varepsilon \beta_{b r}$ which have sufficient capacity margin (typically, at least 20-30\%). These branches will be further examined for TCSC installation.

3) Do two OPF runs with relaxed voltage constraints; the first with original reactances, whilst the reactance of the considered branch ij $\varepsilon \beta_{b r}$ is modified by pre-specified increment in the second run. The reduction in load and generation curtailments at node $m$ is denoted by $\triangle B E E N S_{i j, m}^{t h}$ and $\triangle B E S P_{i j, m}^{t h}$.

4) Step 3 can also be done to include highly loaded branches into TCSC ranking, which is analogous to voltage interior regions (5) and (6). In that case, both OPF runs are done with thermal ratings of highly loaded branches reduced by $\psi \mathrm{pu}$.

5) Find the total weighted daily reduction in load and wind curtailments due to change in reactance $x_{i j}$ :

$\triangle B E N S \& S P_{i j}=$

$\tau_{1} \cdot \sum_{m \in \beta_{E N S}} \Delta B E E N S_{i j, m}^{t h}+\tau_{2} \cdot \sum_{m \in \beta_{E S P}} \Delta B E S P_{i j, m}^{t h}$

which is used to find a TCSC ranking list in descending order.

\section{c) Algorithm for Placement of SVCs and TCSCs}

Expected daily load curtailments due to violation of voltage and thermal constraints, BEENS ${ }^{\text {volt }}$ and $B E E N S^{\text {th }}$, as well as expected daily spillages caused by voltage and thermal constraints, $B E S P^{\text {volt }}$ and $B E S P^{\text {th }}$, are then used to define the best locations for placement for SVCs and TCSCs:

1) Where linear combination of curtailed wind and load due to voltage problems $c e^{\text {volt }}=\left(\tau_{1} \cdot B E E N S^{\text {volt }}+\tau_{2} \cdot B E S P^{\text {volt }}\right)$ is greater than the curtailed energy due to thermal problems $c e^{t h}=\left(\tau_{1} \cdot B E E N S^{t h}+\tau_{2} \cdot B E S P^{t h}\right)$, a top-ranked SVC is installed and $\mathrm{SMCS}^{2}$ is run; otherwise, the highest ranked TCSC is placed and SMCS ${ }^{2}$ is run.

2) The $\mathrm{SMCS}^{2}$ results give a new set of load and wind curtailments BEENS $S^{\text {volt }}, B E E N S^{\text {th }}, B E S P^{\text {volt }}$ and BESP ${ }^{\text {th }}$. They are used to determine whether a SVC or TCSC is installed in the next step using the same logic as in step No. 1.

3) The above procedure is repeated until:

- either improvement in load and wind curtailments is considered insignificant, or,

- the FACTS investment budget is spent.

\section{SECOND SimUlation STAGE}

The models specific to the second simulation stage are presented below.

\section{A. Optimum Power Flow Model}

The OPF model is adapted to include load and wind curtailments and FACTS. Its mathematical formulation is:

$$
\begin{aligned}
& \min \left\{z=\sum_{j} C_{G j} \cdot\left(P_{G j}+P_{W G j}\right)+\sum_{i} V O L L_{i} \cdot L C_{i}+\sum_{j} \xi_{j} \cdot V S P_{j}+\right. \\
& \left.\sum_{j} \xi_{j} \cdot I V S P_{j}\right\} \\
& \text { s/to: } \\
& \quad\left(P_{G i}+P_{W G i}-V S P_{i}-I V S P_{i}\right)-\left(P_{D i}-L C_{i}\right)-\sum_{i j} P_{i j}(\cdot)=0 \\
& \quad Q_{G i}+Q_{S V C i}-\left(Q_{D i}-\operatorname{tg}\left(\varphi_{i}\right) \cdot L C_{i}\right)-\sum_{i j} Q_{i j}(\cdot)=0 \\
& \quad I_{i j}(\cdot) \leq I_{i j}^{S T R / R T T R}
\end{aligned}
$$

$$
\begin{aligned}
& V^{\min } \leq V_{i} \leq V^{\max } \\
& P_{G j}^{\min } \leq P_{G j} \leq P_{G j}^{\max } \\
& Q_{G j}^{\min } \leq Q_{G j} \leq Q_{G j}^{\max } \\
& P_{W G j}^{u p} \leq P_{W G j} \leq P_{W G j}^{u p} \\
& 0 \leq V S P_{j} \leq V S P_{j}^{\max } \\
& 0 \leq I V S P_{j} \leq I V S P_{j}^{\max }-V S P_{j}^{\max } \\
& 0 \leq L C_{i} \leq P_{D i} \\
& Q_{S V C i}^{\min } \leq Q_{S V C i} \leq Q_{S V C i}^{\max } \\
& X_{T C S C i j}^{\min } \leq X_{T C S C i j} \leq X_{T C S C i j}^{\max }
\end{aligned}
$$

where $C_{G j}$ is marginal cost of dispatchable generation $P_{G j}$ or wind $P_{W G j}$ at node $j, V O L L_{i}$ is value of the lost load [30] - load curtailment $L C_{i}$ at node $i, \xi_{j}$ is cost of either voluntary $V S P_{j}$ or involuntary spillage $I V S P_{j}$ at node $j$ (relations (3)), $Q_{G i}$ and $Q_{S V C i}$ are reactive power productions of a dispatchable generator and an SVC at node $i, P_{D i}, Q_{D i}$ and $\varphi_{i}$ are active load, reactive load and load angle at node $i, P_{i j}(\cdot), Q_{i j}(\cdot)$ and $I_{i j}(\cdot)$ are active power, reactive power and current flows in branch $i j$ that are functions of unknown terminal voltages and angles [31], as well as TCSC reactances:

$$
\begin{aligned}
P_{i j}(\cdot) & =V_{i}^{2} g_{i j}^{T C S C}-V_{i} V_{j}\left(g_{i j}^{T C S C} \cos \theta_{i j}+b_{i j}^{T C S C} \sin \theta_{i j}\right) \\
Q_{i j}(\cdot) & =-V_{i}^{2} b_{i j}^{T C S C}+V_{i} V_{j}\left(b_{i j}^{T C S C} \cos \theta_{i j}-g_{i j}^{T C S C} \sin \theta_{i j}\right) \\
I_{i j}(\cdot) & =\left[I_{r i j}(\cdot)^{2}+I_{m i j}(\cdot)^{2}\right]^{0.5} \\
I_{r i j}(\cdot) & =g_{i j}^{T C S C}\left(V_{i} \cos \theta_{i j}-V_{j} \cos \theta_{i j}\right)-b_{i j}^{T C S C}\left(V_{i} \sin \theta_{i j}-V_{j} \sin \theta_{i j}\right) \\
I_{m i j}(\cdot) & =g_{i j}^{T C S C}\left(V_{i} \sin \theta_{i j}-V_{j} \sin \theta_{i j}\right)+b_{i j}^{T C S C}\left(V_{i} \cos \theta_{i j}-V_{j} \cos \theta_{i j}\right)
\end{aligned}
$$

where branch current $I_{i j}(\cdot)$ is expressed through real $I_{r i j}(\cdot)$ and imaginary $I_{m i j}(\cdot)$ parts. Relations (22) - (26) show that branch conductance $g_{i j}^{T C S C}$ and susceptance $b_{i j}^{T C S C}$ can also be calculated for branches with a TCSC reactance, in which case branch impedance is $z_{i j}=r_{i j}+\left(x_{i j}-X_{T C S C i j}\right)$. Next, $I_{i j}^{S T R / R T T R}$ is either STR or RTTR rating of branch $i j, V_{i}$ is voltage magnitude at node $i, P_{W G j}$ is active wind generation at node $j$ set at the sampled value $P_{W G j}^{u p}$, and $X_{T C S C i j}$ is reactance of TCSC in branch $i j$. The lower and upper limit values are denoted by superscripts ${ }^{\min }$ and ${ }^{\max }$, respectively.

The objective of the optimization model (9) - (26) is to minimize hourly operational costs, which consist of four terms: generation cost, cost of curtailed loads and costs of voluntary and involuntary wind spillages. Equations (10) and (11) model active and reactive power balances at all nodes; it is assumed that wind generators operate at unity power factor. A constant power factor is assumed for each nodal load, giving reactive power curtailment $\operatorname{tg}\left(\varphi_{i}\right) \cdot L C_{i}$ in (11).

Thermal constraints of all branches are expressed by inequalities (12), in which either STR or RTTR is used for OHL. Voltage constraints are given by (13) and limitations on dispatchable generation are modelled with (14) and (15). Inequalities (16) specify the non-dispatchable level of wind generations, whilst limits on voluntary and involuntary 

HERE TO EDIT) <

spillages are defined by (17) and (18); note the total spillage $I V S P_{j}^{\max }$ must be less than wind production $P_{W G j}^{u p}$. Limits on load curtailments are shown in (19), whilst constraints on SVC and TCSC devices are defined by (20) and (21). SVCs are modelled as reactive power sources; inequalities (21) are implicitly modeled by adjusting branch reactances.

\section{B. Maximization of Wind Deployment}

In several analyzed scenaria, particularly when FACTS and/or RTTR are deployed, wind spillage levels can be below the contractual values. In such cases, it is possible to increase capacities of installed wind units.

The $\mathrm{SMCS}^{2}$ results are delivered on an hourly basis and for the whole day. The expected hourly spillages are compared against the contractual spillage and deployed wind generations are uniformly increased in hours with spillages smaller than contractual obligations. A heuristic relation between the wind generation increase and spillage increase is used to decide how much to increment deployed wind generation in each step. The procedure is iteratively repeated and maximum deployable wind generations are calculated on an hourly basis.

This procedure can be extended to increase and/or decrease deployable hourly wind generation in such a way that the expected daily spillage does not exceed contracted threshold.

\section{Outputs}

The reliability indices are EENS, expected frequency (EFI) and expected duration of load interruptions $(E D I)$. The wind spillage indices are expected spillage $(E S P)$, expected spillage frequency $(E S P F)$ and duration (ESPD) calculated as in [32].

Calculated hourly operational cost contains four terms: a) Cost of generations $C_{G}(t)$; b) Cost of load curtailments $C_{L C}(t)$; c) Cost of voluntary wind spillage $C_{V S P}(t)$; and d) Cost of involuntary wind spillage $C_{I V S P}(t)$. When studying two alternative solutions, change in daily operational cost is:

$\Delta O C O S T=\sum_{t=1}^{24}\left[\Delta C_{G}(t)+\Delta C_{L C}(t)+\Delta C_{V S P}(t)+\Delta C_{I V S P}(t)\right]$

The probability distribution functions (PDFs) of operational costs, as well as costs of voluntary and involuntary spillages and load curtailments are calculated on an hourly basis. These curves can be used to quantify the financial risk of implementing a particular strategy. The concept of value-atrisk (VaR) [30] was applied to measure potentially 'excessive' costs. Assuming network costs $(N C)$ denote any category of costs, the corresponding cumulative distribution function (CDF) is used to calculate the $\mathrm{VaR}$ at confidence level $\alpha$ [30]:

$$
\operatorname{VaR}_{1-a}^{N C}\left(N C_{X}\right)=\sup \left\{N C_{1-a} \in R: C D F_{N C_{X}}\left(N C_{1-a}\right) \leq 1-a\right\}
$$

where $N C_{X}$ is cost that is not exceeded with probability $(1-\alpha)$.

\section{NETWORK DATA AND CASE STUdIES}

\section{A. Test Network}

The original test network IEEE-RTS 96 was modified in the following way: all scenarios assume an increase in load by $1.31 \mathrm{pu}$ and an increase of $0.55 \mathrm{pu}$ and $0.6 \mathrm{pu}$ transmission capacity for the $138 \mathrm{kV}$ and $230 \mathrm{kV}$ levels, respectively. Wind farms are then connected at nine sites in an attempt to emulate $7 \mathrm{UK}$ areas listed in Fig. 2. It was assumed that they operate at
PQ mode with wind factor $w f$ equal to $16.6 \%$ [33] and that they deliver $20 \%$ of the peak load [34], which is equivalent to $745 \mathrm{MW}$ on the studied network. Geographically $80 \%$ of the wind farms' capacity is installed in the northern part (buses $13,14,15,18 \& 19)$, while $20 \%$ of capacity is in the southern part (buses 1, 2, $7 \& 8$ ). The total wind farm capacity is $4470 \mathrm{MW}$ and is delivered from 447 wind turbines.

To calculate power outputs of wind turbines (WTGs), it was assumed that cut-in, rated, and cut-out speeds are 14.4, 36, and $80 \mathrm{~km} / \mathrm{h}$, respectively [34]. Failure rates and average repair times of WTG are two failures/year and 44 hours [13]. A simple ACSR technology was assumed for RTTR calculations [32]; conductor temperature is set to $60^{\circ} \mathrm{C}$ for system normal and to $75^{\circ} \mathrm{C}$ for system emergencies [32].

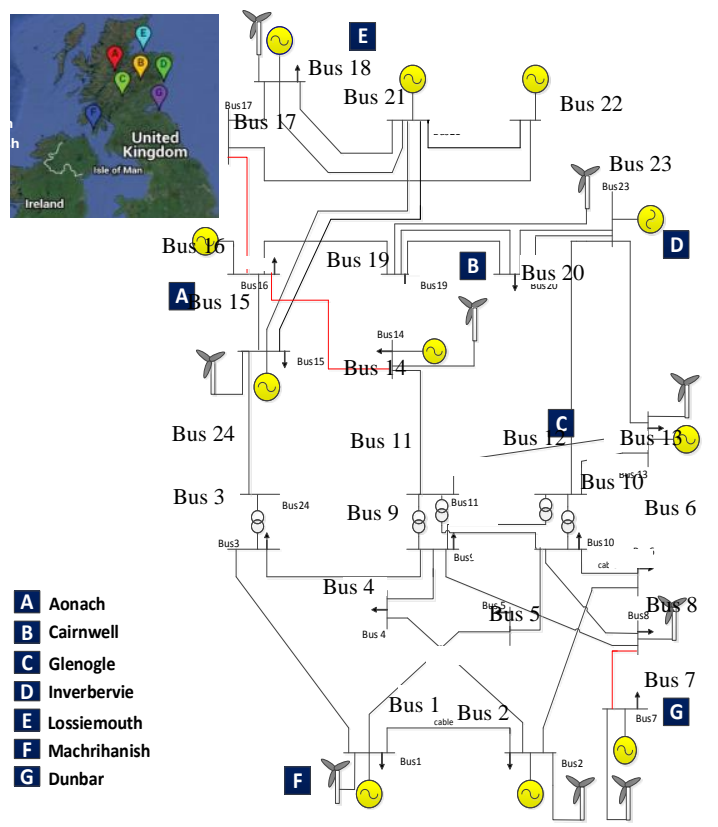

Fig. 2: Modified test network

Average values of 5-year hourly weather data are obtained from the BADC MIDAS metheorogical stations in 7 UK areas - Fig. 2 [35]. Finally, SVCs operated in the range -100MVar to 100MVar, whilst reactances of TCSCs were in the range $X_{T C S C i j}^{\min }=0.7 X_{i j}$ to $X_{T C S C i j}^{\max }=1.2 X_{i j}$. The initial weights $\tau_{1}$ and $\tau_{2}$ were set to 0.5 and modified in sensitivity studies.

\section{B. Developed Study Cases}

Combinations of several factors, shown in the first column of Table I, are done to define the study cases. Both SMCS and state enumeration analyses are used in all scenarios. The deployed wind sources can be maximized to meet contractual obligations $\left(\vartheta_{S P L}=+1\right)$, or no modification of wind capacities is done $\left(\vartheta_{S P L}=0\right)$. The second factor shows whether the cost of wind spillages is included $(\xi \neq 0)$ or not $(\xi=0)$ in the OPF. The installation of an SVC is denoted by $f_{1}=1$, whilst $f_{2}=1$ means a TCSC is placed. The last factor, $p$, shows whether OHL STR is used $(p=0)$ or RTTR is calculated $(p=1)$. All studies are repeated for winter peak demand (first day of week 50 ) and summer minimum demand ( $7^{\text {th }}$ day of $38^{\text {th }}$ week). 

HERE TO EDIT) <

TABLE I - MODELLING SCENARIOS FOR MAXIMUM WIND UTILIZATION

\begin{tabular}{c|c|c|c|c|c|c|c|c|c}
\hline \hline & $\mathrm{S} 1$ & $\mathrm{~S} 2$ & $\mathrm{~S} 3$ & $\mathrm{~S} 4$ & $\mathrm{~S} 5$ & $\mathrm{~S} 6$ & $\mathrm{~S} 7$ & $\mathrm{~S} 8$ & $\mathrm{~S} 9$ \\
\hline$\vartheta_{S P L}$ & 0 & 0 & +1 & 0 & +1 & 0 & +1 & 0 & +1 \\
$\xi$ & 0 & $\neq 0$ & $\neq 0$ & $\neq 0$ & $\neq 0$ & $\neq 0$ & $\neq 0$ & $\neq 0$ & $\neq 0$ \\
$f_{1}$ & 0,1 & 0 & 0 & 0 & 0 & 1 & 1 & 1 & 1 \\
$f_{2}$ & 0,1 & 0 & 0 & 0 & 0 & 1 & 1 & 1 & 1 \\
$p$ & 0 & 0 & 0 & 1 & 1 & 0 & 0 & 1 & 1 \\
\hline \hline
\end{tabular}

Nine developed scenarios are shown in Table I. Scenario $S 1$ is the base case, where wind capacities are not maximized, unity spillage costs and STR of OHL are used in the OPF. In $S 1$, the ranking lists of FACTS are initially defined $\left(f_{l}=0\right.$ and $\left.f_{2}=0\right)$ and then used for the optimum FACTS placement $\left(f_{l}=1\right.$ and $\left.f_{2}=1\right)$. Scenario $S 2$ does not modify deployed wind capacities $\left(\vartheta_{S P L}=+O\right)$ but applies wind spillage costs in the OPF to minimize wind spillages. Scenario $S 3$ maximizes deployable wind $\left(\vartheta_{S P L}=+1\right)$ using wind spillage costs in order to match the wind spillage contractual value. Scenario $S 4$ is similar to $S 2$ but incorporates RTTR of OHL as a corrective action in the OPF, whilst scenario S5 maximizes deployed wind $\left(\vartheta_{S P L}=+1\right)$ and applies RTTR. Scenario S6 incorporates SVC or TCSC to find minimum wind spillages, whereas scenario $S 7$ deploys an SVC or a TCSC to maximize deployed wind $\left(\vartheta_{S P L}=+1\right)$. Scenarios $S 8$ and $S 9$ are similar to $S 6$ and $S 7$; they apply both SVC and TCSC as well as RTTR.

\section{ANALYSIS OF CASE STUDIES}

The entire methodology is coded in Matlab which makes use of Matpower [36]. Essential results are presented below.

\section{A. Ranking and Placement of SVC and TCSC}

Scenario $S 1$ is used to produce FACTS ranking lists after the SMCS $^{1}$ and then to define best locations for SVCs and TCSCs. Table II shows SVC ranking list, the base expected spillages $B E S P^{\text {volt }}$ and the base expected energy not supplied BEENS $S^{\text {volt }}$ due to voltage constraints, as well as the voltage deviations $\left(\Delta \gamma^{V_{\min / \max }}\right)$ from minimum $(0.95 \mathrm{pu})$ and maximum limits (1.05pu) within the internal region of $\psi=1 \%$. The presented ranking was obtained for $\tau_{1}=\tau_{2}=0.5$ and it remains unchanged until $\tau_{1}=0.7$ and $\tau_{2}=0.3$.

\begin{tabular}{cccccc}
\multicolumn{5}{c}{ TABLE II-SVC RANKING LIST } \\
\hline \hline $\begin{array}{c}\text { Wind } \\
\text { buses }\end{array}$ & $\rho_{i}$ & $\begin{array}{c}\text { BESP } \\
(\mathrm{MW})\end{array}$ & $\begin{array}{c}\text { BEENS } \\
\text { volt } \\
(\mathrm{MW})\end{array}$ & $\Delta \gamma_{i}^{V^{\min }}$ & $\Delta \gamma_{i}^{V^{\max }}$ \\
\hline b18 & 14.1288 & 27.82 & 0.02 & 0.008 & 0.007 \\
b7 & 12.0456 & 5.50 & 18.40 & 0.008 & 0 \\
b19 & 11.4408 & 22.66 & 0.04 & 0.008 & 0 \\
b14 & 11.2687 & 22.37 & 0.1 & 0.002 & 0.001 \\
b8 & 10.9218 & 9.52 & 12.28 & 0.001 & 0.001 \\
b1 & 10.8990 & 21.73 & 0.003 & 0.002 & 0.001 \\
b13 & 3.7004 & 7.07 & 0.2 & 0.018 & 0 \\
b2 & 2.8721 & 5.73 & 0 & 0.001 & 0.0015 \\
b15 & 2.0694 & 3.87 & 0.16 & 0.017 & 0.01 \\
\hline \hline
\end{tabular}

The SVC ranking list is based on criterion (7) and it shows that the best locations are buses $\mathrm{b} 18, \mathrm{~b} 7, \mathrm{~b} 19, \mathrm{~b} 14, \mathrm{~b} 8$ and $\mathrm{b} 1$ if $\tau_{1}=\tau_{2}$. This is because voltage spillages $B E S P^{\text {volt }}$ are very high at these buses, whilst $B E E N S^{\text {volt }}$ is high only at $\mathrm{b} 7$ and b8. Had we chosen $\tau_{1} \gg \tau_{2}$, nodes $\mathrm{b} 7$ and $\mathrm{b} 8$ would be on the top of the list. The lowest feasible-internal voltages are at b13 and b15, whilst b18 has highest feasible voltages; this may indicate problems at these nodes in future.

TABLE III- TCSC RANKING LIST

\begin{tabular}{cccc}
\hline \hline Line & $\Delta B E N S \& S P_{i j}$ & $\Delta B E S P_{i j}^{\text {th }}(\mathrm{MW})$ & $\Delta B E E N S_{i j}^{\text {th }}(\mathrm{MW})$ \\
\hline$(15,24)$ & 8.11 & 16.2 & 0.02 \\
$(7,8)$ & 7.64 & 10.9 & 4.38 \\
$(8,9)$ & 7.6 & 12.12 & 3.14 \\
$(15,16)$ & 7.5 & 13.16 & 0.01 \\
$(2,6)$ & 5.073 & 7.42 & 2.72 \\
$(13,23)$ & 3.9 & 7.87 & 0.028 \\
$(8,10)$ & 3.32 & 4.6 & 2.04 \\
$(14,16)$ & 2.61 & 5.12 & 0.1 \\
\hline \hline
\end{tabular}

TABLE IV-BEST LOCATIONS FOR FACTS PLACEMENT

\begin{tabular}{c|ccc|c|cccc}
\hline \hline & c $e^{\text {volt }}$ & $>$ & $c e^{\text {th }}$ & & $c e^{\text {volt }}$ & $>$ & $c e^{\text {th }}$ \\
\hline BaseSMC & 88.74 & $<$ & 104.13 & b14 & 80.80 & $>$ & 76.71 \\
$(15,24)$ & 96.12 & $>$ & 95.02 & b8 & 76.01 & $<$ & 76.93 \\
b18 & 94.97 & $>$ & 94.42 & $(15,16)$ & 75.75 & $>$ & 74.31 \\
b7 & 89.05 & $<$ & 93.82 & $(2,6)$ & 74.08 & $>$ & 70.28 \\
$(7,8)$ & 88.58 & $>$ & 86.01 & b1 & 74.01 & IS & 70.12 \\
b19 & 85.11 & $<$ & 86.29 & b13 & 74.99 & IS & 71.01 \\
$(8,9)$ & 86.94 & $>$ & 76.87 & $(13,23)$ & 74.06 & IS & 70.03 \\
\hline \hline
\end{tabular}

The ranking list of branches for TCSC placement is shown in Table III. The thermal reductions $\triangle B E E N S^{\text {th }}$ indicate that lines $(7,8),(8,9) \&(2,6)$ are the best locations, whilst lines $(15,24),(8,9)$ and $(15,16)$ give highest thermal spillage reductions $\triangle B E S P^{\text {th }}$. The maximum spillage reduction of 13.16 MW is for line $(15,16)$ where the initial $B E S P^{\text {th }}$ was $58 \mathrm{MW}$.

Best locations for placement of SVCs and TCSCs are shown in Table IV. It is based on the comparison of wind and load curtailments due to voltage $c e^{\text {volt }}$ and thermal constraints $c e^{\text {th }}$. Where $c e^{\text {th }}>c e^{\text {volt }}$ the first TCSC from the ranking list is placed in line $(i, j)$; otherwise, the first SVC is connected to bus " $b$ ". Every time an SVC or TCSC is installed, the difference in EENS and ESP is checked against the threshold value and if considered insignificant ('IS'), the next device is studied. Here, TCSC on line $(15,24)$ reduces $c e^{\text {th }}$ but increases $c e^{\text {volt }}$ compared to the base SMCS ${ }^{1}$; however, the total curtailed energy $c e^{\text {volt }}$ plus $c e^{\text {th }}$ is always reduced. The last three cases in Table IV show no desired improvement in curtailed energy. Consequently, nodes b18, b7, b19, b14 and b8 should be considered for SVC installation, whilst lines $(15,24),(7,8)$, $(8,9),(15,16)$ and $(2,6)$ for TCSC placement. The available budget will determine the actual FACTS installations.

\section{B. Prioritization of wind spillages}

Scenario $S 1$ with unit spillage costs in the OPF is used to evaluate base wind spillages BESP and marginal prices $\mu$, required for the calculation of wind spillage cost coefficients (eq. (3) \& (4)) that are used in the OPF for scenario $S 2$. Fig. 3 compares scenarios $S 1$ and $S 2$ and shows how the mean percentage value of wind spillage at each wind generation node decreases for both days and both study methods when cost coefficients are applied in $S 2$. The largest decrease (33\%) in spillage occurs at bus 8 in winter, whilst in summer, wind spillage decreases by $20 \%$ at bus 13 . The $\mathrm{SMCS}^{2}$ reduces wind spillage in the total system by $10.8 \%$ in winter and $13.11 \%$ in 

HERE TO EDIT) <

summer, whilst these figures are respectively, $24 \%$ and $22 \%$ for the state enumeration analysis.

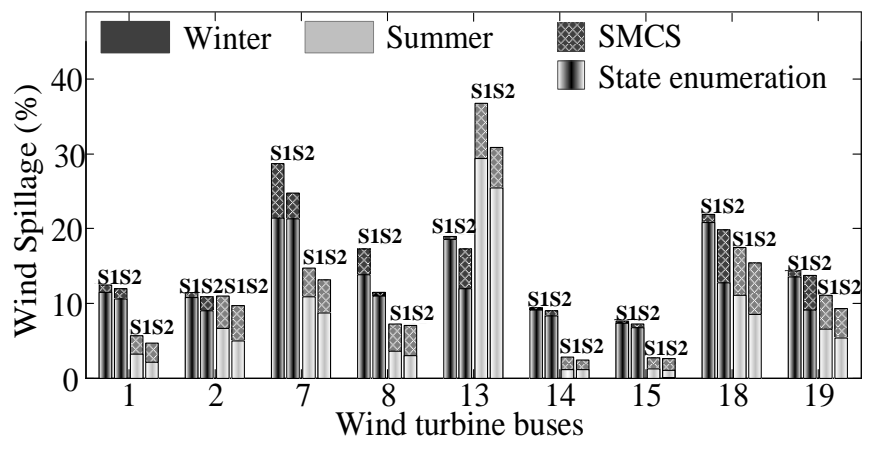

Fig. 3: Wind spillages under scenario $S 1$ and scenario $S 2$

\section{Impact of Controls \& Maximized Deployed Wind Capacity}

The initially installed wind capacity of 4470MW, found from (1) and (2), is first used to calculate the optimal wind spillages. The box plots of optimal wind spillages for the SMCS analysis of scenarios $S 1, S 4, S 6\left(f_{1}\right), S 6\left(f_{2}\right) \& S 8$ with initially connected wind sources are shown in Fig. 4 (winter) and Fig. 5 (summer); median values are horizontal lines inside boxes separating lower and upper quartiles. Spillages are higher in all cases in winter due to increased network stress. Scenario $S 8$ with a combination of SVC, TCSC \& RTTR gives the best minimized spillages, with a reduction of $31.65 \%$ in winter and $33.44 \%$ in summer when compared to $S 1$. The second best spillage is for $\mathrm{S} 6\left(f_{2}\right)$ giving reduction of $22.8 \%$ (winter), and then reduction of $22.3 \%$ for $\mathrm{S} 6\left(f_{1}\right)$ (summer). A normal distribution was found to best-fit the wind spillage PDF in winter, whilst a log-normal distribution best fit summer spillage PDF.

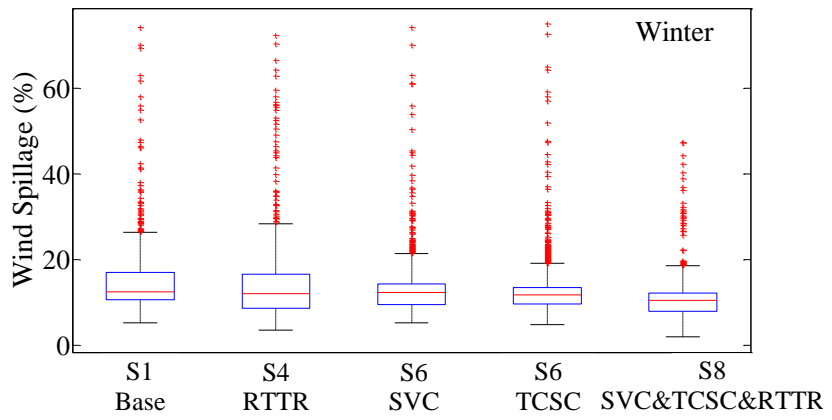

Fig. 4: SMCS winter wind spillages for scenarios $S 1, S 4, S 6\left(f_{1}\right), S 6\left(f_{2}\right) \& S 8$

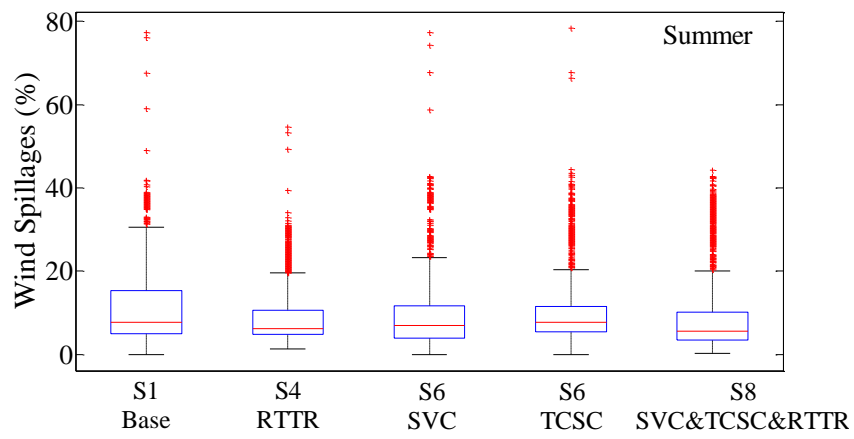

Fig. 5: SMCS summer wind spillages for scenarios $S 1, S 4, S 6\left(f_{1}\right), S 6\left(f_{2}\right) \& S 8$
The maximum integrated wind power that meets contractual obligations is calculated using the SMCS and stateenumeration for the following cases (Fig. 6): a) $S 3$ with prioritized spillage costs; b) $S 5$ with RTTR; c) $S 7$ with SVC $\left(f_{1}=1\right)$; d) $S 7$ with TCSC $\left(f_{2}=1\right)$; and e) $S 9$ with SVC, TCSC \& RTTR. In all cases, it was possible to deploy more wind in the winter and summer days, where deployed wind in winter was always higher than in summer mainly because winter STR or RTTR is higher than summer STR/RTTR and winter wind speeds are higher than in summer.

The first solution, prioritization of wind spillages, can integrate $\sim 6-7 \%$ additional wind, whilst the best results are obtained for a combination of a SVC, TCSC and RTTR, where it is possible to integrate an additional $22-23 \%$ in winter and $17-18 \%$ in summer. However, the ranking of the other three controls S5(RTTR), S7(SVC) and S7(TCSC) is different in both days when either the SMCS or state enumeration is used.

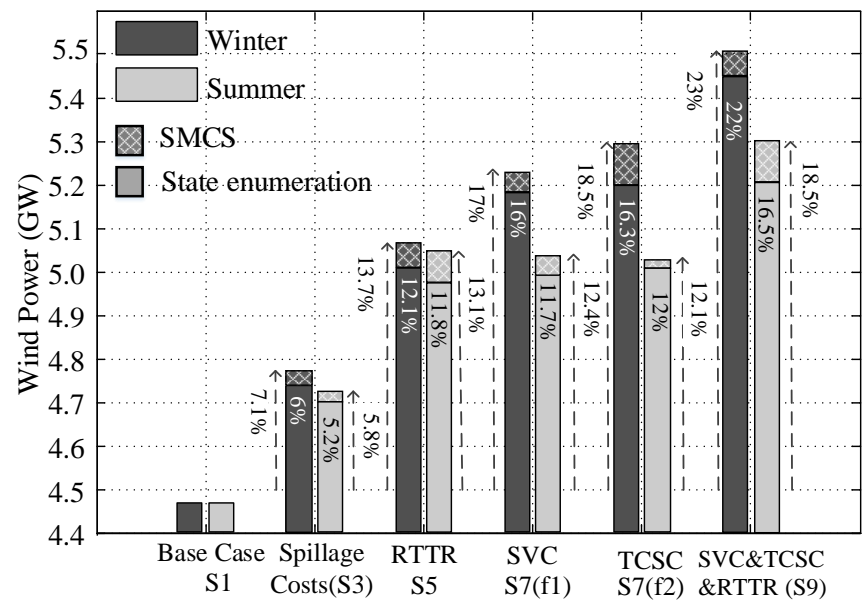

Fig. 6: Maximum deployed wind capacity under scenarios $S 3, S 5, S 7 \& S 9$

Finally, a comparison of results from Figs. 4, 5 and 6 shows that although installing TCSCs can give a slightly higher wind integration than SVCs (Fig. 6), probabilistic wind spillages in the system with SVCs can be lower than with TCSCs (Figs. 4, 5). This means that both problems need to be studied separately, and the preferred solution is likely to be the one that maximizes wind deployment.

Table V summarises reliability indices for the SMCS studies. It is shown that $S 8$ is the most reliable both in terms of load and spillage indices; reduction in EENS is $24 \%$ in winter and $79 \%$ in summer when compared to $S 1$. The spillage indicators are also significantly lower; for example, ESPD drops from 5.93 to $3.15 \mathrm{~h} / \mathrm{d}$. Scenario $S 2$ with non-zero spillage costs gives significantly reduced ESP and ESPF, whilst EENS is slightly lower. The use of RTTR in scenario $S 4$ results in substantial reduction in EENS, which is a consequence of greater utilization of the three most critical lines $(16,14)$, $(16,17), \&(7,8)$; the wind spillage indicators are also reduced. Installation of FACTS contributes to improving network reliability by $9.38 \%$ in EENS for SVC $\left(S 6-f_{l}\right)$ and $14.2 \%$ for TCSC $\left(S 6-f_{2}\right)$ compared to $S 1$. SVCs and TCSCs also improve spillage indices in varying degrees depending on the season. 

HERE TO EDIT) <

TABLE V - LOAD AND SPILLAGE RELIABILITY INDICES

\begin{tabular}{|c|c|c|c|c|c|c|c|}
\hline & & $\mathrm{S} 1$ & $\mathrm{~S} 2$ & S4 & S6(SVC) & S6(TCSC) & S8 \\
\hline EENS & Wint & 86.4 & 84.7 & 75.1 & 78.3 & 74.1 & 65.9 \\
\hline$(\mathrm{MWh} / \mathrm{d})$ & Sum & 6.42 & 4.16 & 3.72 & 3.81 & 3.75 & 1.34 \\
\hline EDI & Wint & 2.67 & 2.65 & 2.41 & 2.65 & 2.63 & 2.12 \\
\hline$\left(* 10^{-2} \mathrm{~h} / \mathrm{d}\right)$ & Sum & 0.47 & 0.54 & 0.51 & 0.53 & 0.52 & 0.50 \\
\hline EFI & Wint & 2.39 & 2.37 & 1.98 & 2.03 & 2.01 & 2.01 \\
\hline$\left(* 10^{-2} \mathrm{int} / \mathrm{d}\right)$ & Sum & 0.19 & 0.12 & 0.09 & 0.12 & 0.11 & 0.10 \\
\hline ESP & Wint & 15.8 & 14.1 & 13.1 & 12.5 & 12.2 & 10.8 \\
\hline$(\% / \mathrm{d})$ & Sum & 12.2 & 10.6 & 8.53 & 9.5 & 9.8 & 8.12 \\
\hline ESPF & Wint & 1.9 & 1.51 & 0.73 & 1.19 & 1.24 & 1.07 \\
\hline (int/d) & Sum & 1.24 & 1.02 & 0.08 & 1.12 & 1.15 & 0.09 \\
\hline ESPD & Wint & 5.93 & 5.84 & 3.69 & 5.15 & 4.76 & 3.15 \\
\hline$(\mathrm{h} / \mathrm{d})$ & Sum & 5.66 & 4.76 & 3.58 & 3.86 & 4.51 & 3.12 \\
\hline
\end{tabular}

\section{Impact of FACTS and RTTR on Operation Costs}

Operation costs for different scenarios and cost savings between the scenarios and base case $S 1$ are quantified in terms of VaR metrics at different confidence levels $\alpha$. Fig. 7 shows VaR metrics for scenario $S 4$ with RTTR, S6 with SVC, S6 with TCSC and $S 8$ with SVC,TCSC\&RTTR. Black area indicates savings between $S 6(\mathrm{SVC})$ and base case $S 1$, dark grey between $S 6$ (TCSC) and $S 6(\mathrm{SVC})$, less dark grey between S4(RTTR) and S6(TCSC), and light grey area between $S 8$ (SVC,TCSC\&RTTR) and S4(RTTR). S8(SVC,TCSC\& RTTR) shows the highest savings compared to $S 1$ by $45 \%$ considering $\mathrm{VaR}_{95 \%}^{\mathrm{NC}}$. It is apparent that applied controls give greater savings for higher confidence intervals. Unlike, when $\alpha=60 \%$ the savings are almost negligible, showing how average conditions give little information about the wind system.

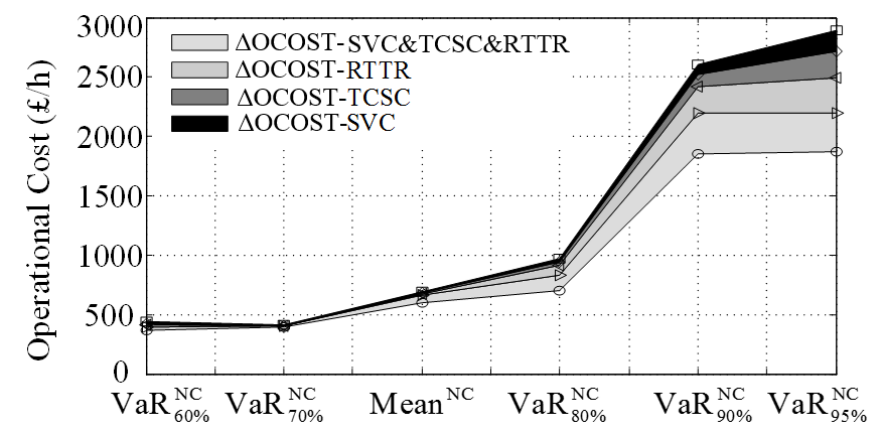

Fig.7: Operating costs: $S 4$ (RTTR), S6(SVC), S6(TCSC), $S 8$ (SVC,TCSC\&RTTR)

\section{E. Computational CPU Times}

All simulations are performed on an i7-3820 processor with 32GB RAM. The optimization model (9)-(26) is solved using MIPS Matpower solver in Matlab [36]. The CPU times are presented in Table VI for scenario $S I$ and all scenarios related to the maximized deployed wind. Times required to solve best locations of FACTS devices are relatively high due to the iterative nature of the algorithm - section III.D.

\begin{tabular}{cc|c|c|c|c|c|c}
\multicolumn{6}{c}{ TABLE VI-COMPUTATIONAL CPU TIMES FOR MAIN SCENARIA } \\
\hline \hline & $\begin{array}{c}\text { S1 } \\
\text { Base } \\
\text { case }\end{array}$ & $\begin{array}{c}\text { FACTS } \\
\text { Opt. }\end{array}$ & $\xi \neq 0$ & RTTR & SVC & TCSC & $\begin{array}{c}\text { SVC\&TCSC } \\
\text { \&RTTR }\end{array}$ \\
\hline CPU(s) & 3689 & 7273 & 3812 & 5129 & 3720 & 5248 & 6664 \\
\hline \hline
\end{tabular}

\section{CONCLUSIONS}

A probabilistic methodology for maximizing deployed wind sources whilst minimizing curtailed wind to meet contractual obligations is proposed in this paper. Impacts of wind spillage prioritization, deployment of FACTS devices and real-time thermal ratings on maximized wind utilization, system reliability and operating costs are investigated for day-ahead planning.

Case studies have shown that wind spillage prioritization in the OPF can substantially reduce optimal spillage levels, up to $10.8 \%$ for a typical winter- and $13.11 \%$ for a typical summerday. It is shown that the implementation of SVC \& TCSC \& RTTR allows up to $23 \%$ more wind sources to be integrated. However, ranking of the applied controls based on the maximized wind utilization can differ when SMCS or state enumeration is used. Next, the control that gives minimum spillages usually does not give the maximum integrated wind capacity and vice versa. Improvements in EENS and other reliability indices are also shown. It can be concluded that the application of multiple reliability indicators can be a good choice for optimal operational decisions related to the wind management.

Future work is focused on the extension of the proposed probabilistic approach to long-term planning in order to find the optimal connection wind capacities, as well as the optimal operation of energy storage for wind systems.

\section{REFERENCES}

[1] M. Gibescu, W. L. Kling, B. C. Ummels, E. Pelgrum, and R. A. van Offeren, "Case study for the integration of $12 \mathrm{GW}$ wind power in the Dutch power system by 2020," 2009 CIGRE/IEEE PES Joint Symposium Integration Wide-Scale Renewable Resources Into Power Delivery System, 2009.

[2] B. C. Ummels, E. Pelgrum, M. Gibescu, and W. L. Kling, "Comparison of integration solutions for wind power in the Netherlands," IET Ren. Power Gen., vol.3, no. 3, pp.279-292, 2009.

[3] A. B. T. Attya and T. Hartkopf, "Utilising stored wind energy by hydro-pumped storage to provide frequency support at high levels of wind energy penetration," IET Generation, Transmission \& Distribution, vol. 9, no. 12, pp. 1485-1497, 2015.

[4] R. Billinton and R. Karki, "Maintaining supply reliability of small isolated power systems using renewable energy," IEE Proceedings Generation, Transmission \& Distribution, no. 6, 2001.

[5] F. Bouffard and F. D. Galiana, "Stochastic security for operations planning with significant wind power generation," IEEE Trans. on. Power Systems, vol. 23, no. 2, pp. 306-316, 2008.

[6] H. Klinge Jacobsen and S. T. Schröder, "Curtailment of renewable generation: Economic optimality and incentives," Energy Policy, vol. 49, pp. 663-675, 2012.

[7] B. Cleary, A. Duffy, A. O'Connor, M. Conlon, and V. Fthenakis, "Assessing the Economic Benefits of Compressed Air Energy Storage for Mitigating Wind Curtailment," IEEE Trans. on Sustainable Energy, vol. 6, no. 3, pp. 1021-1028, 2015.

[8] RTE, "RTE Business and sustainable development report 2015," 2015.

[9] A. Evans, V. Strezov, and T. J. Evans, "Assessment of utility energy storage options for increased renewable energy penetration," Renew. and Sustain. Energy Reviews, vol. 16, no. 6, pp. 4141-4147, 2012.

N. Zhang, C. Kang, D. S. Kirschen, Q. Xia, W. Xi, et al,"Planning Pumped Storage Capacity for Wind Power Integration,"IEEE Trans. on Sustainable Energy,vol. 4, no. 2, pp.393-401, 2013.

D. J. Burke and M. J. O'Malley, "Maximizing firm wind connection to security constrained transmission networks," IEEE Trans. on Power Systems, vol. 25, no. 2, pp. 749-759, 2010. 
[12] D. J. Burke and M. J. O'Malley, "A study of optimal nonfirm wind capacity connection to congested transmission systems," IEEE Trans. on Sustainable Energy, vol. 2, no. 2, pp. 167-176, 2011.

[13] R. Billinton and W. Wangdee, "Reliability-Based Transmission Reinforcement Planning Associated With Large-Scale Wind Farms," IEEE Trans. on Power Systems., vol. 22, no. 1, pp. 34-41, Feb. 2007.

[14] Salehi-Dobakhshari and M. Fotuhi-Firuzabad, "Integration of largescale wind farm projects including system reliability analysis," IET Renewable Power Generation, vol. 5, no. 1, p. 89, 2011.

[15] M. A. Abdullah, K. M. Muttaqi, D. Sutanto, and A. P. Agalgaonkar, "An Effective Power Dispatch Control Strategy to Improve Generation Schedulability and Supply Reliability of a Wind Farm Using a Battery Energy Storage System," IEEE Trans. on Sustainable Energy, vol. 6, no. 3, pp. 1093-1102, 2015.

[16] M. A. Hozouri, A. Abbaspour, M. Fotuhi-Firuzabad, and M. Moeini-Aghtaie, "On the Use of Pumped Storage for Wind Energy Maximization in Transmission-Constrained Power Systems," IEEE Trans. on Power Systems, vol. 30, no. 2, pp. 1017-1025, 2015.

[17] H. Park and R. Baldick, "Transmission planning under uncertainties of wind and load: Sequential approximation approach," IEEE Trans. on Power Systems, vol. 28, no. 3, pp. 2395-2402, 2013.

[18] J. Zhu, K. Cheung, D. Hwang, and A. Sadjadpour, "Operation strategy for improving voltage profile and reducing system loss," IEEE Trans. Power Delivery, vol. 25, no. 1, pp. 390-397, 2010.

[19] E. Ghahremani, and I. Kamwa, "Optimal placement of MultipleType FACTS devices to Maximize Power System Loadability Using a Generic Graphical User Interface ,"IEEE Trans. on Power Systems, vol. 28, no. 2, pp. 764-778, 2013.

[20] A. L. Ara, A. Kazemi, S. A. N. Niaki, and S. Member, "Multiobjective Optimal Location of FACTS Shunt-Series Controllers for Power System Operation Planning," IEEE Trans. on Power Delivery, vol. 27, no. 2, pp. 481-490, 2012.

[21] M. J. Hossain, H. R. Pota, M. A. Mahmud, and R. A. Ramos, "Investigation of the Impacts of Large-Scale Wind Power penetration on the Angle and Voltage Stability of Power Systems," IEEE Systems Journal, vol. 6, no. 1, pp. 76-84, 2012.

[22] F. B. Alhasawi and J. V. Milanovic, "Techno-Economic Contribution of FACTS Devices to the Operation of Power Systems With High Level of Wind Power Integration," IEEE Trans. on Power Systems, vol. 27, no. 3, pp. 1414-1421, 2012.

[23] A. Nasri, A. Conejo, S. Kazempour, M. Ghandhari, "Minimizing Wind Power Spillage Using an OPF with FACTS Devices," IEEE Trans. on Power Systems, vol. 29, no. 5, pp. 2150-2159, 2014.

[24] Ofgem, "DCUSA: Schedule 17 - EHV Charging Methodology (Forward Cost Pricing Model)", UK, October 2012.

[25] RTE,"http://www.rtefrance.com/sites/default/files/apercu_energie_ elec_2016_05_an.pdf," 2016.

[26] R. Billinton and W. Li, Reliability Assessment of Electrical Power Systems Using Monte Carlo Methods, London: Plenum, 1994.

[27] J. Schachter and P. Mancarella, "A Short-Term Load Forecasting Model for Demand Response Applications," in IEEE Int. Conf. on the European Energy Market, 2014, pp. 1-5.

[28] ER P27, "Current Rating Guide for High Voltage Overhead Lines Operating in the UK Distribution System," ENA, London, 1986.

[29] "IEEE Standard for Calculating the Current-Temperature of Bare Overhead Conductors," IEEE Std 738-2006, pp. 1-59, 2007.

[30] A. Shapiro and S. Basak, "Value-at-Risk Based Risk Management: Optimal Policies and Asset Prices," Rev. Financ. Stud., vol. 14, no. 2, pp. 371-405, 2001.

[31] M. Lavorato, J. F. Franco, M. J. Rider, and R. Romero, "Imposing radiality constraints in distribution system optimization problems," IEEE Trans. Power Systems, vol. 27, no. 1, pp. 172-180, 2012.

[32] K. Kopsidas, A. Kapetanaki, and V. Levi, "Optimal Demand Response Scheduling with Real Time Thermal Ratings of Overhead Lines for Improved Network Reliability," IEEE Trans. on Smart Grid, 2016.

[33] Department of Energy and Climate Change, "Digest of UK Energy Statistics: Renewable sources of energy," 2014, pp. 157-193.

[34] K. Soren, M. Poul-Eric, and A. Shimon, "Wind energy implications of large-scale deployment on the GB electricity system", London: Royal Academy of Engineering, April 2014.

[35] "http://badc.nerc.ac.uk/data/ukmo-midas/WPS.html."
[36] R. D. Zimmerman, E. M.-S. Carlos, and D. Gan, "MATPOWER: A MATLAB Power System Simulation Package, Version 3.1b2, User's Manual." PSERC, Tech. Rep. 2006, New York, 2011. 